\title{
Rigorous Modeling of Solution Gas - Oil Ratios for a Wide Ranges of Reservoir Fluid Properties
}

\author{
Arash Kamari ${ }^{1}$, Sohrab Zendehboudi ${ }^{2}$, James J Sheng ${ }^{3 *}$, Amir H Mohammadi ${ }^{1,4 *}$ and Deresh Ramjugernath ${ }^{1}$ \\ ${ }^{1}$ Thermodynamics Research Unit, School of Chemical Engineering, University of Kwa-Zulu-Natal, Howard College Campus, King George V Avenue, Durban 4041, South \\ Africa \\ ${ }^{2}$ Department of Chemical Engineering, Massachusetts Institute of Technology (MIT), Cambridge, MA 02139, USA \\ ${ }^{3}$ Department of Petroleum Engineering, Texas Tech University, TX, USA \\ ${ }^{4}$ Institute of Research in Chemical Engineering and Petroleum (IRGCP), Paris Cedex, France
}

\begin{abstract}
The reservoir fluid properties, the solution gas-oil ratio (GOR), are of great importance in various aspects of petroleum engineering. Therefore, a rapid means for estimating such parameters is much sort after. In this study, the linear interaction and general optimization method is applied in the development of a precise and reliable model for estimating the solution GOR. In order to develop a model that would be comprehensive, a reliable and extensive databank comprising of more than 1000 datasets collected from various geographical locations, including Asia, Mediterranean Basin, North America, Africa, and Middle East was compiled. Furthermore, the model developed was benchmarked against widely-used empirical methods in order to evaluate the performance of method proposed in predicting solution GOR data. The results show that the model proposed in this study outperforms the empirical methods to which it was compared. This study also investigated the influence of the reservoir fluid properties on the estimated solution GOR for the newly-developed model. Results show that bubble point pressure and gas gravity have the largest and the smallest influences on the predicted solution GOR, respectively. Finally, the Leverage approach was applied to determine the applicability domain for the proposed method via the detection of outlier data points. It was determined that only 26 data points, out of more than 1000 data, are identified as outlier data points.
\end{abstract}

Keywords: Reservoir fluid properties; Solution gas-oil ratio; GOR; API; Outlier data

Abbreviations: AARD: Average Absolute Relative Deviation; APRE: Average Percent Relative Error; API: Oil API Gravity; EOR: Enhanced Oil Recovery; LINGO: Linear Interactive And General Optimizer; OFVF: Oil Formation Volume Factor; Pb: Bubble Point Pressure, Psi; Rs: Solution Gas-Oil Ratio, SCF/STB; RMSE: Root Mean Square Error; SCF: Standard Cubic Feet; STB: Stock Tank Barrel; TR: Reservoir Temperature, ${ }^{\circ} \mathrm{F}$; $\Gamma$ g: Gas Specific Gravity.

\section{Introduction}

The properties of reservoir fluids [1] are normally determined from bottom-hole and/or surface recombined samples. The fluid properties are required for a large number of reservoir engineering calculations, which include, selection of the most important enhanced oil recovery (EOR) method for a reservoir candidate, estimation of hydrocarbon reserves, performance prediction, calculations related to the production operation, production optimization, well-testing studies, fluid flow through porous media, etc [1-10]. In other words, reservoir fluid properties such as bubble point pressure, oil formation volume factor (OFVF), and solution GOR are key parameters in petroleum engineering calculations and are obtained through laboratory measurements, theoretical methods, and/or empirically derived correlations. Generally, petroleum engineers seek a rapid way to obtain these parameters, taking into account both economic and technical issues. The determination of reservoir fluid properties using laboratory experiments are not simple and can be time-consuming and expensive [11-13]. The reservoir fluid properties, in the absence of experimental measurements, must be determined through empirical methods.

Over the years, various empirical methods have been reported for the determination of reservoir fluid properties related to oil samples from different geographical locations worldwide. To this end, in one of the first attempts, Elam [14] in 1957 proposed a correlation for the estimation of saturation pressure as a function of temperature, gas specific gravity, oil gravity and solution GOR using as a basis of 231 data points for Texas crude oil. One year later, Lasater [15] presented a bubble point-pressure correlation for black oil data taken from Canada, western and mid-continental USA and South America. His model was developed using 158 samples of 137 various crude oils. He reported an average error of $3.8 \%$ for his model. He also observed that the existence of $\mathrm{CO}_{2}$ in crude oil samples results in an increment in the saturation pressure. Vasquez and Beggs [16] proposed some empirically derived methods for the estimation of reservoir fluid properties using a universal databank collected from various regions of the world. Moreover, they separated the experimentally obtained data into two classes. The first group contained oils with gravities less than $30^{\circ} \mathrm{API}$. The second group contained oils with gravities more than $30^{\circ} \mathrm{API}$. In contrast with Lasater's results [15], they found that $\mathrm{CO}_{2}$ content decreases the saturation pressure.

In 1983, Ostermann [17] developed two correlations for the estimation of saturation pressure of crude oil samples taken from

"Corresponding authors: Sheng J, Department of Petroleum Engineering, Texas Tech University, TX, USA, Tel: 806-834-8477; E-mail: james.sheng@ttu.edu

Amir H Mohammadi, Institute of Research in Chemical Engineering and Petroleum (IRGCP), Paris Cedex, France, Tel: + (33) 164-694-970. Fax: + (33) 164-694-968 E-mail: mohammadi@ukzn.ac.za; amir-hossein.mohammadi@mines-paristech.fr

Received September 12, 2016; Accepted October 30, 2016; Published November 07, 2016

Citation: Kamari A, Zendehboudi S, Sheng JJ, Mohammadi AH, Ramjugernath D (2016) Rigorous Modeling of Solution Gas-Oil Ratios for a Wide Ranges of Reservoir Fluid Properties. J Pet Environ Biotechnol 7: 308. doi: 10.4172/2157. 7463.1000308

Copyright: ( 2016 Kamari A, et al. This is an open-access article distributed under the terms of the Creative Commons Attribution License, which permits unrestricted use, distribution, and reproduction in any medium, provided the original author and source are credited. 
different regions in Alaska based on a limited number of data points. Al-Marhoun [9] developed an empirical correlation applying data gathered from the Middle East region. In 1990, Rollins et al. [18] proposed an empirically derived method to calculate the stock-tank gas-oil ratio as a function of oil API gravity, separator pressure and temperature, and gas gravity. In the same year, Sutton and Farshad [19] reviewed several PVT correlations and compared the accuracy of each model for several PVT parameters for application in the Gulf of Mexico. In their study, Glaso's correlations [20] provided acceptable results for calculation of saturation pressure, solution GOR, and OFVF. They reported that Vazquez and Begg's correlations [16] had higher accuracy for solution GOR for more than 1400 SCF/STB and saturation pressures more than 7000 psi. In 1992, Dokla and Osman [21] studied 51 crude oil samples from UAE and developed a new empirical methods for OFVF, saturation pressure and solution GOR. They reported that PVT correlations should be derived using local data sets because universal correlations are not always accurate enough. Moreover, Omar and Todd [22] developed models for OFVF and saturation pressure on the basis of Standing's correlations [23] using 93 PVT datasets from Malaysian oil reservoirs. Their models showed better accuracy for Malaysian oil samples. Furthermore, Petrosky and Farshad [24] proposed some empirically derived methods for the determination of reservoir fluid properties using data collected from the Gulf of Mexico. They showed that the empirical methods proposed outperformed other methods developed for the Gulf of Mexico, involving those reported by Standing [23], Vasquez and Beggs [16], Glaso [20], and Al-Marhoun [9]. Elsharkawy et al. [25] also compared different correlations to characterize Kuwaiti crude oils using a limited number of oil samples in this year.

Ghetto et al. [26] proposed some empirical methods for the calculation of saturation pressure, solution GOR, OFVF, oil compressibility, and oil viscosity for heavy and extra-heavy oils. The data used in developing the correlations came from reservoir fluid samples extracted from the Mediterranean Basin, Africa, and the Persian Gulf. In 1998, Khairy et al. [27] developed some empirical methods for the estimation of saturation pressure and bubble point OFVF. They compared their model with nine published correlations. In 1999, Velarde and McCain [28] developed a set of empirical methods for calculating solution GOR and OFVF, and modified OFVF using 195 laboratory tests. In 2007, Mazandarani and Asghari [29] tuned AlMarhoun 's correlation [9] for Iranian field data to obtain a modified correlation using about fifty fluid samples collected from different Iranian oil fields. In 2008, Taghaz et al. [30] tested the accuracy of PVT correlations to determine the solution GOR of Libyan oils using about 1600 data points from different oil fields in the Sirte basin. They concluded that no correlation is suitable for Libyan oils. In 2012, Shafiie et al. [31] optimized Standing [23] and McCain correlations for solution GOR and OFVF, based on Iranian crude oil samples, and developed a new model using Genetic Algorithms. Very recently, Arabloo et al. [11] developed simple and accurate empirical methods for the prediction of saturation pressure and OFVF using a large databank compiled from various geographical locations. Here, it is worth mentioning that smart techniques have previously been implemented for the estimation of reservoir fluid properties and petroleum engineering problems in addition to empirical methods [32-40].

In this study, the LINGO (Linear Interactive and General Optimizer) [41] methodology is implemented to propose an efficient, precise, and rapid-to-use model for the determination of solution
GOR. To achieve a comprehensive model covering properties for all regions, a reliable databank was collected which comprises an extensive range of reservoir conditions, as well as PVT properties. The widelyused empirically derived correlations were used for comparison to benchmark the performance of the model proposed in this study. To this end, an error analysis was conducted graphically and statistically. The influence of the reservoir fluid properties on the solution GOR values calculated were also studied. Finally, applicability domain of the proposed method was determined through the detection of outlier data points using Leverage approach.

\section{Solution Gas-Oil Ratio}

As mentioned above, the solution GOR plays a key role in PVT analysis related to petroleum engineering calculations. As a consequence, solution GOR affects the OFVF, the viscosity compressibility of oil, and it is also needed to determine the in-situ total reservoir fluid rates. As a definition, solution GOR is the amount gas dissolved in oil with regards pressure. Here, it should be noted that reservoirs containing light oils have more dissolved gas than a reservoir with heavy oils. With an increase in pressure, solution GOR increases approximately linearly until the attainment of bubble point/saturation pressure $\left(\mathrm{P}_{\mathrm{b}}\right)$; after which it is a constant and the oil is supposed to be under-saturated (Figure 1). Figure 1 is a typical illustration of the trend of solution GOR versus pressure.

As a result, most of empirically derived methods reported in the open literature for the determination of reservoir fluid properties have been developed on the basis of data related to a specific region and limited PVT studies [42]. This drawback can decrease the precision of these methods in predicting reservoir fluid properties at a particular solution gas-oil ratio. This means that the aforementioned empirical correlations may lead to significant deviation when they are utilized for the estimation of reservoir fluid properties for other geographical locations. For that reason, it is of important to collect a comprehensive databank covering a wide range of reservoir fluid properties for all regions in the world. Therefore, a reliable and comprehensive databank $[9,17,21,22,26,43-47]$ comprising more than 1000 data series collected from various geographical locations including Asia, Mediterranean Basin, North America, Africa, and Middle East was compiled in this study. The databank collected includes reservoir fluid properties, viz. solution GOR $\left(\mathrm{R}_{\mathrm{s}}, \mathrm{SCF} / \mathrm{BBL}\right)$, bubble point pressure $\left(\mathrm{P}_{\mathrm{b}}, \mathrm{psi}\right)$, reservoir temperature $\left(\mathrm{T}_{\mathrm{R}},{ }^{\circ} \mathrm{F}\right)$, and gas gravity $\left(\gamma_{\mathrm{g}}\right)$, as well as oil gravity (API). A statistical description of the properties, including maximum, minimum, and average values is summarized in Table 1.

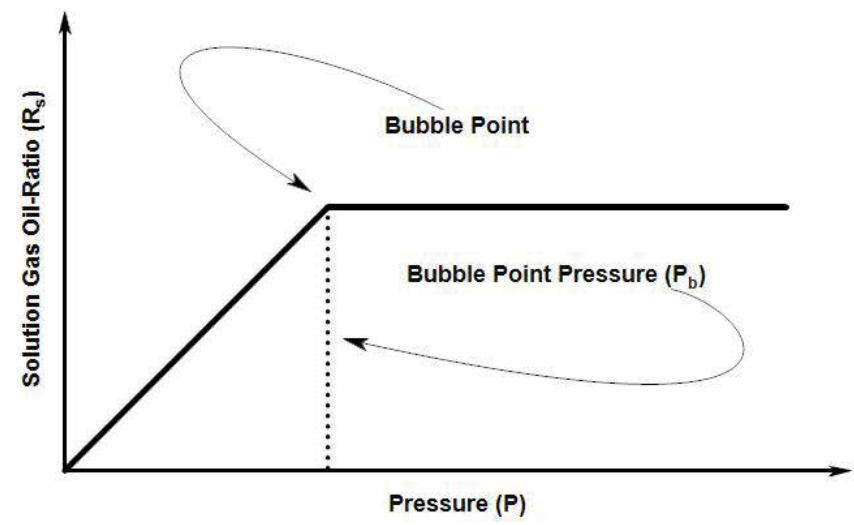

Figure 1: Typical trend of solution GOR versus pressure. 


\begin{tabular}{|c|c|c|c|c|c|}
\hline Property & Unit & Minimum & Average & Maximum & Role \\
\hline $\mathrm{R}_{\mathrm{s}}$ & SCF/STB & 7.08 & 515.32 & 3298.66 & Output \\
\hline $\mathrm{vg}$ & - & 0.52 & 1.00 & 3.44 & Input \\
\hline $\mathrm{T}_{\mathrm{R}}$ & ${ }^{\circ} \mathrm{F}$ & 54.9 & 173.30 & 360.93 & Input \\
\hline $\mathrm{API}$ & - & 6.00 & 33.41 & 56.8 & Input \\
\hline $\mathrm{P}_{\mathrm{b}}$ & $\mathrm{psi}$ & 58.01 & 1755.58 & 7127.01 & Input \\
\hline
\end{tabular}

Table 1: Statistical analysis of reservoir fluid properties used for the estimation of solution gas-oil ratio.

\section{Proposing the New Model}

The key aim of the present study is to propose a comprehensive, accurate and reliable model for the determination of solution GOR using data collected from various crudes worldwide. To this end, the LINGO methodology [41] is used for pursuing our objective in this study. Basically, the technique is an interactive linear and discrete tuning tool. As a result, the methodology has been utilized in mathematics, science, and industry, and employed to solve computer problems mathematically [48-50]. Furthermore, quadratic programming, as well as linear and nonlinear, and integer programming are the most important problems solved by LINGO software [11]. Additionally, the LINGO methodology can solve the root and algebraic equations/ problems linearly and nonlinearly. It should be mentioned that the LINGO software includes a number of common mathematical functions within the programming language to use by operators for finding/solving their programming problem [51]. In this study, the LINGO methodology is used to develop a reliable model to determine the solution GOR as a function of reservoir fluid properties, including bubble point/saturation pressure, reservoir temperature, and gas gravity, as well as oil gravity (API) as follows:

$$
R_{s}=f\left(\gamma_{\mathrm{g}}, T_{R}, A P I, P_{b}\right)
$$

In the development of the model, the databank collected was separated into two sets of data, viz. the training and test sets. Approximately $80 \%$ of entire the databank was used in the development of model (training set), and the rest (20\%) was assigned to the test set for checking the model developed and evaluating its accuracy, performance, and capability. To measure the accuracy of the model developed, the average absolute relative deviation (AARD) is selected as an objective function. Finally, a simple form of equation with four easy functions including $\times,+,-, /$ was obtained as follows:

$$
\mathrm{RS}=\mathrm{A}+\mathrm{B}-15.849
$$

$$
\begin{aligned}
& A=0.14624 P_{b}-0.14624 A P I+\frac{802.44}{P_{b}}+\frac{\left(2.727 P_{b}-A P I T_{R}+2715.5\right)^{2}}{(A P I-995.53)^{2}} \\
& \mathrm{~B}=\left(0.0064332 \mathrm{P}_{b}+0.0064332 A P I_{g}\right) \times\left(A P I \gamma_{g}-14.811\right)
\end{aligned}
$$

where $P_{b}$ denotes the bubble point pressure (psi), API stands for oil API gravity, $T_{R}$ denotes the reservoir temperature $\left({ }^{\circ} \mathrm{F}\right)$, and $\gamma_{g}$ is gas specific gravity.

\section{Variables Relevancy Analysis}

To show the degree of dependency of the reservoir fluid properties selected as input variables (i.e. saturation pressure, reservoir temperature, and gas specific gravity as well as oil API gravity) on the solution GORs estimated by Eq. (2), a sensitivity analysis was performed. Hence, the relevancy factor ( $r$ ) [52] is utilized in this study for measuring the degree of effect of each reservoir fluid property applied in Eq. (2) for the determination of solution GOR. Regarding the relevancy factor approach, an input variable has a higher influence on the output parameter if the calculated absolute value of $r$ between the input and output variables is greater than the $r$ values for other input variables. Consequently, the positive or negative influence of input variables (saturation pressure, reservoir temperature, and gas specific gravity as well as oil API gravity) on the solution GORs is however not determined by an absolute value of $r$. Consequently, following equation is used to calculate the $\mathrm{r}$ values through the relevancy analysis [40]:

$$
\mathrm{r}\left(\operatorname{Inp}_{\mathrm{k}}, \mu_{\mathrm{g}}\right)=\frac{\sum_{\mathrm{i}=1}^{\mathrm{n}}\left(\operatorname{Inp}_{\mathrm{k}, \mathrm{i}}-\overline{\operatorname{Inp}_{\mathrm{k}}}\right)\left(\mu_{\mathrm{i}}-\bar{\mu}\right)}{\sqrt{\sum_{\mathrm{i}=1}^{\mathrm{n}}\left(\operatorname{Inp}_{\mathrm{k}, \mathrm{i}}-\overline{\operatorname{Inp}_{\mathrm{k}}}\right)^{2} \sum_{\mathrm{i}=1}^{\mathrm{n}}\left(\mu_{\mathrm{i}}-\bar{\mu}\right)^{2}}}
$$

where $\operatorname{Inp}_{\mathrm{k}, \mathrm{i}}$ stands for $i^{\text {th }}$ value of the $k$ th input variables and $\overline{\operatorname{Inp}_{k}}$ denotes the average value of the $k$ th input variables (i.e. bubble point pressure, reservoir temperature, and gas gravity as well as oil gravity), $\mu_{\mathrm{i}}$ indicates the $i$ th value of the solution gas-oil ratios determined by Eq. (2), and $\mu$ is the average value of the solution gas-oil ratios determined by Eq. (2).

\section{Results and Discussion}

\section{Performance evaluation of the new model}

A graphical and statistical error analysis was conducted to evaluate the performance of the method over a wide range of the reservoir fluid properties, and to compare the results obtained using the model against the most widely used empirically derived correlations. Hence, AARD, root mean square error (RMSE), and average relative percent error (ARPE) were considered as statistical error parameters, and a parity diagram or scatter plot, as well as a relative distribution error curve are used as two graphical illustrations to evaluate the performance of the method proposed to estimate the solution GORs. The results of error analysis are summarized in Table 2. The results in the table indicate that the model proposed has acceptable accuracy with respect to the large number of data points and the wide range of reservoir fluid properties employed in its development. The AARD value reported for the model is $19.83 \%$. The value indicates that the method output values are in agreement with corresponding experimental records of the solution GOR. Furthermore, the calculated APRE and RMSE values are $1.73 \%$ and 203.05, respectively.

To assess the performance of the proposed model graphically, a scatter diagram, as well as a relative distribution error plot of values estimated using Eq. (2) were plotted. Figure 2 shows a comparison of values estimated by the model developed in this study versus experimental values of solution GOR on a parity diagram. It is clear

\begin{tabular}{|c|c|c|c|}
\hline Method & AARD, \% & APRE, $\%$ & RMSE \\
\hline Glaso [20] & 79.25 & 32.37 & 468.33 \\
\hline Petrosky and Farshad [24] & 62.70 & -48.16 & 217.38 \\
\hline Kartoatmodjo and Schmidt [54] & 57.80 & -48.15 & 395.93 \\
\hline Standing [23] & 47.84 & -38.61 & 312.88 \\
\hline Farshad et al. [2] & 43.07 & -28.87 & 267.08 \\
\hline Vazquez and Beggs [16] & 42.29 & -31.99 & 389.08 \\
\hline Al-Marhoun [9] & 42.01 & -21.28 & 348.17 \\
\hline Dindoruk and Christman [56] & 36.89 & -13.78 & 254.27 \\
\hline Macary and El-Batanony [53] & 36.54 & 1.40 & 238.87 \\
\hline Al-Shammasi [55] & 32.95 & -16.72 & 242.81 \\
\hline Baniasadi et al. [42] & 23.15 & 2.29 & 197.39 \\
\hline This present study & 19.83 & 1.73 & 203.05 \\
\hline
\end{tabular}

Table 2: Error analysis performed for the proposed model and comparable methods investigated in this study. 


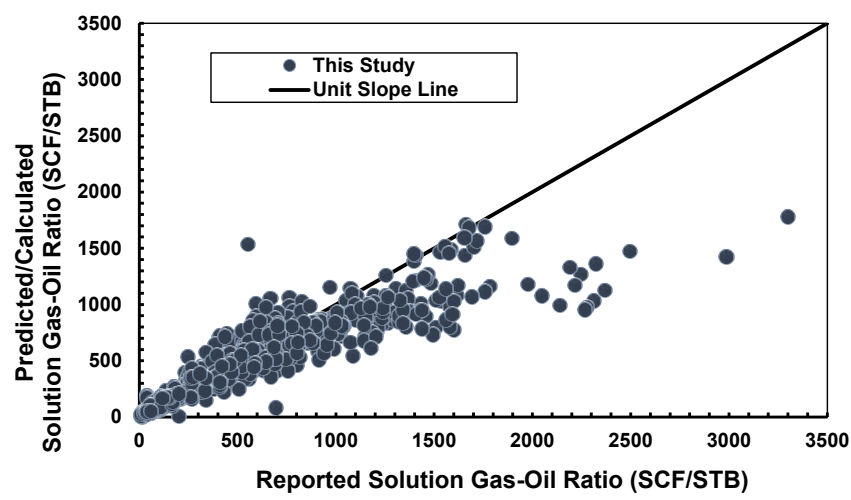

Figure 2: Scatter diagram of the predicted solution gas-oil ratio values versus the experimental records.

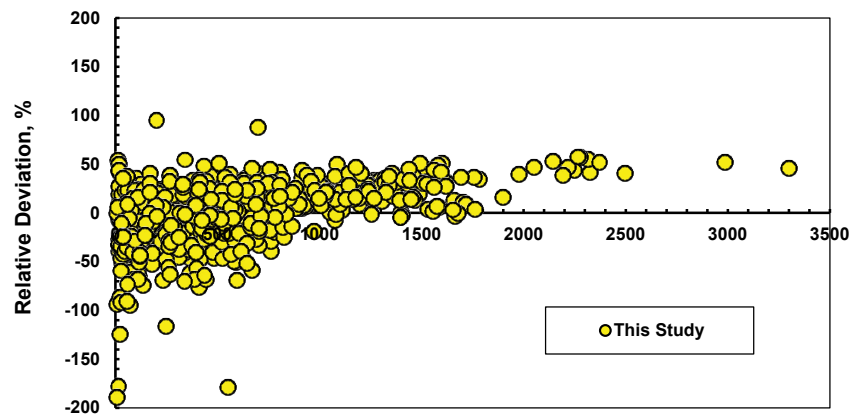

Reported Solution Gas-Oil Ratio (SCF/STB)

Figure 3: Relative error distribution plot of the predicted solution gas-oil ratio values versus the experimental records.

from the figure that the estimated GOR values approximately match the experimental values, resulting in data clustered around the parity line. This shows the capability of the model proposed in this study in predicting more than 1000 data values for solution GOR Another graphical comparison is shown in Figure 3, which illustrates the calculated average relative percent error between the model and experimental data for solution GOR. As can be seen in the figure, the relative errors for the estimated data are clustered around the zero line. This demonstrates that there is acceptable agreement between the model predictions and experimental data for solution GOR. Figure 4 shows the plot of the predicted values against experimental data for the solution GOR with respect to the sorted data index.

A comprehensive comparison analysis was undertaken between the model developed in this study and widely-used empirically derived methods including the Farshad et al. method [2], Macary and ElBatanony method [53], Petrosky and Farshad method [24], Vazquez and Beggs method [16], Al-Marhoun method [9], Kartoatmodjo and Schmidt method [54], Al-Shammasi method [55], Standing method [23], Glaso [20], Baniasadi et al. method [42], and Dindoruk and Christman method [56] in order to evaluate the performance of the method in predicting solution GOR data. Table 2 reports the statistical results obtained for the comparisons undertaken. The table shows that the model developed in this study performs the best model for the calculation of solution GOR. Figure 5 illustrates graphically the calculated AARD for the model developed, as well as all comparative methods investigated in the study. From Table 2 and Figure 5, it can be concluded that the methods of Baniasadi et al. [42], Al-Shammasi
[55], Macary and El-Batanony [53], Dindoruk and Christman [56], and Al-Marhoun [9] are, after the method proposed in this study, the most accurate for the calculation of solution GOR with AARD values of $23.15,32.95,36.54,36.89$, and $42.01 \%$, respectively. Table 3 lists some random data points selected from the databank, and Table 4 summarizes the estimated values for the data points presented in Table 3 using method developed and empirical methods discussed above. Table 4 also confirms superior performance of the model developed in this study over the empirical methods to which it was compared.

\section{Influence of the reservoir fluid properties on solution GOR}

As pointed out earlier, reservoirs containing light oils have more dissolved gases than reservoir with heavy oils. Therefore, it would be interesting to determine the accuracy of the model developed for various ranges of oil API gravity. To this end, the capability of the model presented in this study for estimating the solution GOR was observed across the spectrum of the light to heavy oils. The solution GORs estimated by the proposed model was partitioned into four classes of oil API gravities, viz. 6-15, 15-25, 25-35, and 35-56.8 ${ }^{\circ}$. The results of analysis in terms of the calculated AARD values is shown in Figure 6. As can be seen in the figure, the model errors for the estimation of solution GORs of light oils is less than that for heavy oils. In other words, it can be concluded that the model developed in this study is more applicable for crudes with higher values of oil API gravity. To further investigate the influence of the reservoir fluid properties, including saturation pressure, reservoir temperature, gas specific gravity, and oil API gravity, a sensitivity analysis was performed in this study using the relevancy factor approach. Figure 7 shows the results of sensitivity analysis. The figure indicates that bubble point pressure and

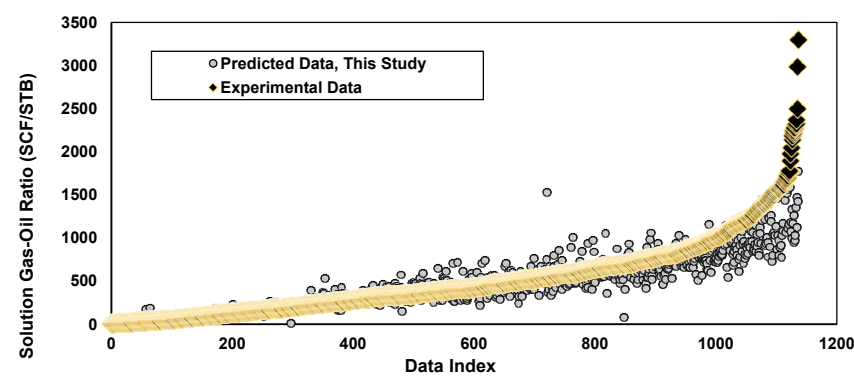

Figure 4: Fitting curve, as sorted data index, for the predicted solution gas-oil ratio values versus the experimental records.

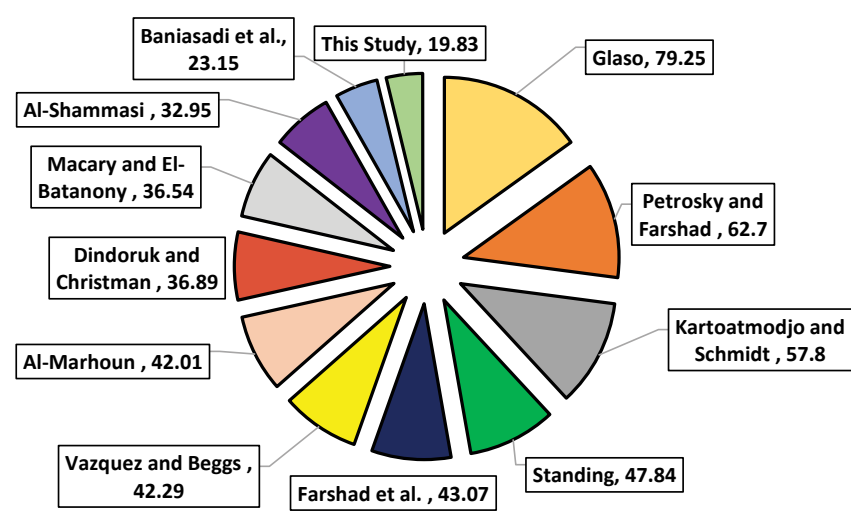

Figure 5: Graphical comparison of the developed model against the comparative methods studied in terms of statistical error parameter of AARD. 


\begin{tabular}{|c|c|c|c|c|c|}
\hline Data Index & $\mathbf{P}_{\mathbf{b}}$ & $\mathbf{V}_{\mathbf{g}}$ & $\mathbf{A P I}$ & $\mathbf{T}_{\mathbf{R}}$ & $\mathbf{R}_{\mathbf{s i}}$ \\
\hline 1 & 2082.77 & 0.756 & 7.5 & 153.5 & 208.7 \\
\hline 2 & 2076.97 & 0.815 & 10.5 & 152.6 & 260.0 \\
\hline 3 & 554.99 & 0.68 & 12 & 74.9 & 52.4 \\
\hline 4 & 599.98 & 0.74 & 14.8 & 82.8 & 68.0 \\
\hline 5 & 825.28 & 1.411 & 19.4 & 172.4 & 177.8 \\
\hline 6 & 3199.97 & 0.75 & 20.9 & 110.5 & 556.2 \\
\hline 7 & 285 & 0.74 & 23 & 114.8 & 32.5 \\
\hline 8 & 430.04 & 1.04 & 25 & 99.4 & 95.5 \\
\hline 9 & 1499.98 & 0.64 & 27 & 107.7 & 239.9 \\
\hline 10 & 909.97 & 0.67 & 30 & 88.25 & 171.8 \\
\hline 11 & 3057 & 0.778 & 32 & 175 & 679.0 \\
\hline 12 & 400.01 & 0.8 & 34 & 71.6 & 76.6 \\
\hline 13 & 2775.01 & 0.823 & 35.7 & 140.5 & 689.4 \\
\hline 14 & 1340 & 0.8 & 36.3 & 87.8 & 313.4 \\
\hline 15 & 1415 & 1.2468 & 37.2 & 248 & 486.0 \\
\hline 16 & 5760.99 & 0.924 & 40.1 & 302 & 1760.6 \\
\hline 17 & 1153.05 & 0.85 & 40.4 & 105.5 & 299.6 \\
\hline 18 & 2221 & 0.693 & 45.3 & 238 & 547.0 \\
\hline 19 & 1386.97 & 0.763 & 46.5 & 116.03 & 367.6 \\
\hline 20 & 1962.07 & 0.78 & 52.5 & 138.25 & 636.7 \\
\hline 21 & 1170.47 & 0.649 & 56.8 & 140.7 & 300.9 \\
\hline
\end{tabular}

Table 3: Records of some data points existing in the databank compiled in this study.

gas specific gravity has the largest and smallest influences, respectively, on the solution GOR values predicted by the model.

\section{Detection of outlier solution GOR data points}

The detection of outlier data points that exist in a databank used to develop a predictive model is important to know in order to determine the applicability domain of the model developed. To this end, the Leverage methodology [57-59] is utilized in this study to identify outlier data points in the solution GOR databank that was compiled. Detailed information on the Leverage methodology in terms of mathematical equations, as well as a step-by-step procedure is reported elsewhere [57-59]. The Williams diagram is sketched to show graphically the applicability domain of the proposed method. The existence of a majority of solution GOR data in the domain $0 \leq \mathrm{H} \leq 0.1428$ and $-3 \leq$ Standardized Residuals $\leq$ demonstrates that the method is statistically valid. The data points which are located in the domain range- $3 \leq$ Standardized Residuals $\leq$ are recognized as valid solution GOR data, and data which are outside the range are considered as outliers. The results show that only 26 data points in the solution GOR databank (among more than 1000 data points) were identified as outlier data points (Figure 8).

\section{Conclusion}

The linear interaction and general optimization method, as a modeling approach, was applied in the development of an accurate and reliable model for calculating solution GOR data. A comprehensive databank comprising more than 1000 data samples collected from various geographical locations was compiled and used to develop a comprehensively applicable model. The performance of the model developed was compared to some widely-used empirical methods. The influence of the reservoir fluid properties on the estimated solution GOR data was also investigated. Finally, applicability domain of the proposed method was determined through the detection of outlier data points using the Leverage approach. It is found that only 26 data points (among more than 1000 data values) are identified as outlier data points. The results obtained indicate that the model proposed in this study outperforms all comparable models studied with an AARD value of $19.83 \%$. The sensitivity analysis conducted in this study indicates that bubble point pressure and gas gravity have the largest and smallest influences, respectively, on the predicted solution GOR data. Furthermore, the model proposed in this study has greater applicability for the estimation of solution GORs for reservoirs containing light oils.

\begin{tabular}{|c|c|c|c|c|c|c|c|c|c|c|c|c|}
\hline $\begin{array}{l}\text { Data } \\
\text { Index }\end{array}$ & $\begin{array}{l}\text { This } \\
\text { Study }\end{array}$ & ARD $\%$ & Baniasadi & ARD $\%$ & D\& Christman & ARD $\%$ & Al-Marhoun & ARD\% & Macary & ARD\% & Al-Shamasi & ARD\% \\
\hline 1 & 219.0 & 4.9 & 102.8 & 50.8 & 291.9 & 39.9 & 194.7 & 6.7 & 288.9 & 38.4 & 199.0 & 4.6 \\
\hline 2 & 250.2 & 3.8 & 150.2 & 42.2 & 323.3 & 24.4 & 260.2 & 0.1 & 310.8 & 19.5 & 236.7 & 9.0 \\
\hline 3 & 52.4 & 0.0 & 39.5 & 28.5 & 78.5 & 42.3 & 35.6 & 35.5 & 64.2 & 42.3 & 43.6 & 3.4 \\
\hline 4 & 66.1 & 2.9 & 57.7 & 15.2 & 92.7 & 36.3 & 50.8 & 25.4 & 75.5 & 36.0 & 59.4 & 6.9 \\
\hline 5 & 174.6 & 1.8 & 36.5 & 6.5 & 91.1 & 133.6 & 40.2 & 3.0 & 40.0 & 2.5 & 28.5 & 27.0 \\
\hline 6 & 555.0 & 0.2 & 38.9 & 22.5 & 53.7 & 69.0 & 20.2 & 36.4 & 44.3 & 70.9 & 27.4 & 5.9 \\
\hline 7 & 30.3 & 6.6 & 170.0 & 17.6 & 167.8 & 18.7 & 142.0 & 31.2 & 161.5 & 4.1 & 170.4 & 1.2 \\
\hline 8 & 80.2 & 16.1 & 669.0 & 12.1 & 631.0 & 17.1 & 856.4 & 12.5 & 1107.4 & 78.3 & 900.9 & 45.0 \\
\hline 9 & 240.4 & 0.2 & 241.8 & 0.8 & 184.0 & 23.3 & 163.4 & 31.9 & 233.7 & 19.4 & 264.7 & 35.2 \\
\hline 10 & 152.3 & 11.3 & 167.3 & 2.6 & 123.2 & 28.3 & 106.1 & 38.2 & 132.3 & 5.6 & 163.9 & 16.9 \\
\hline 11 & 658.8 & 3.0 & 776.1 & 10.2 & 729.1 & 3.5 & 996.8 & 41.5 & 1094.5 & 90.4 & 1064.8 & 85.2 \\
\hline 12 & 75.8 & 1.1 & 324.2 & 5.2 & 257.2 & 24.7 & 364.2 & 6.5 & 265.4 & 4.9 & 366.0 & 31.2 \\
\hline 13 & 678.0 & 1.6 & 749.8 & 23.6 & 653.9 & 7.8 & 665.6 & 9.7 & 909.5 & 83.7 & 967.1 & 95.3 \\
\hline 14 & 311.7 & 0.5 & 331.2 & 5.7 & 250.8 & 20.0 & 344.2 & 9.8 & 252.9 & 1.1 & 362.2 & 41.6 \\
\hline 15 & 490.7 & 1.0 & 366.7 & 3.8 & 404.7 & 6.2 & 591.2 & 55.2 & 200.3 & 47.4 & 356.3 & 6.5 \\
\hline 16 & 1694.3 & 3.8 & 473.4 & 0.4 & 376.5 & 20.2 & 595.1 & 26.2 & 369.2 & 4.1 & 546.3 & 41.9 \\
\hline 17 & 299.5 & 0.0 & 616.6 & 22.1 & 492.0 & 37.8 & 510.4 & 35.5 & 535.7 & 32.3 & 692.3 & 12.5 \\
\hline 18 & 547.4 & 0.1 & 633.3 & 0.1 & 461.5 & 27.2 & 440.4 & 30.5 & 493.2 & 22.2 & 702.5 & 10.8 \\
\hline 19 & 371.2 & 1.0 & 426.7 & 16.1 & 265.6 & 27.8 & 376.6 & 2.5 & 290.3 & 3.2 & 487.6 & 62.5 \\
\hline 20 & 601.4 & 5.5 & 690.7 & 8.5 & 478.9 & 24.8 & 699.1 & 9.8 & 526.9 & 1.4 & 889.1 & 71.1 \\
\hline 21 & 323.9 & 7.6 & 400.1 & 33.0 & 177.6 & 41.0 & 230.1 & 23.5 & 240.0 & 20.2 & 497.8 & 65.4 \\
\hline
\end{tabular}

Table 4: A point-to-point comparison between the results obtained with the proposed model and comparative methods for the experimental records reported in Table 3. 
Citation: Kamari A, Zendehboudi S, Sheng JJ, Mohammadi AH, Ramjugernath D (2016) Rigorous Modeling of Solution Gas-Oil Ratios for a Wide Ranges of Reservoir Fluid Properties. J Pet Environ Biotechnol 7: 308. doi: 10.4172/2157-7463.1000308

Page 6 of 7

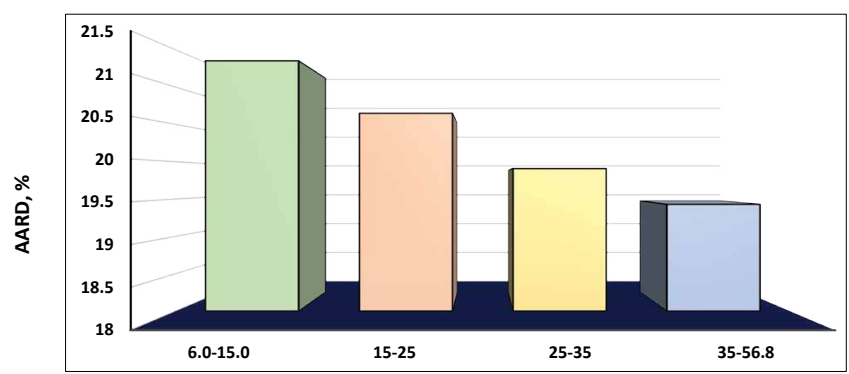

Figure 6: Accuracy of the model developed in this study in different API ranges.

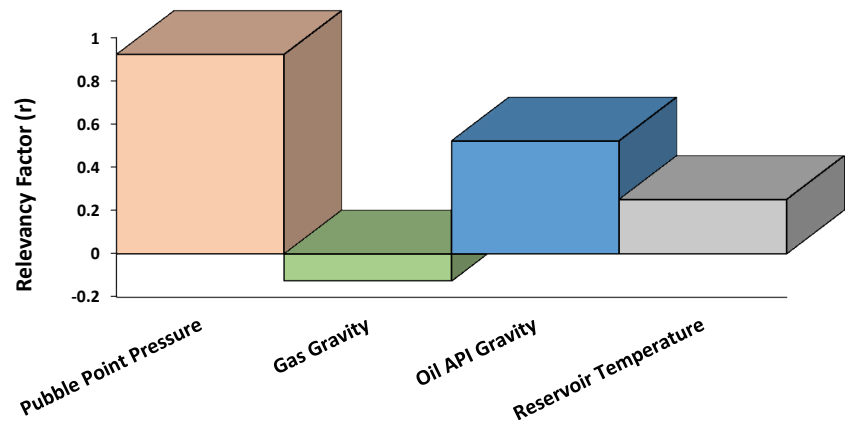

Figure 7: Degree of importance for each input parameter for the prediction of solution gas-oil ratio.

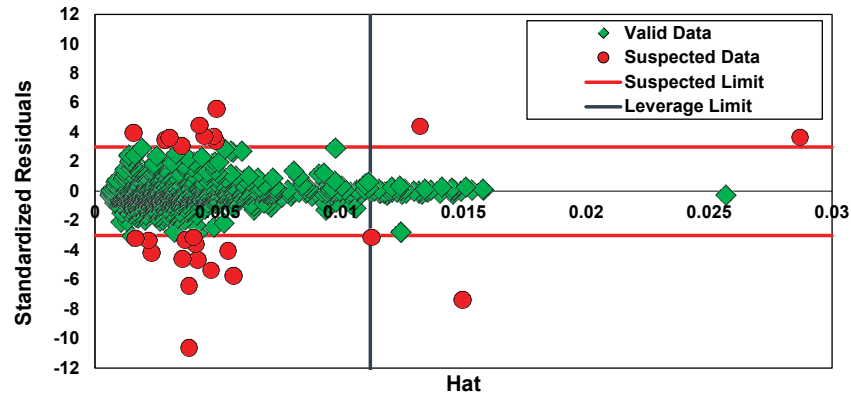

Figure 8: Graphical plot of the leverage analysis for the recognition of outlier data points.

\section{References}

1. Elsharkawy AM, Alikhan AA (1997) Correlations for predicting solution gas/oil ratio, oil formation volume factor and under-saturated oil compressibility. J Pet Sci Eng 17: 291-302.

2. Frashad F, LeBlanc J, Garber J, Osorio J (1996) Empirical PVT correlations for Colombian crude oils, in: SPE Latin America/Caribbean petroleum engineering conference. Society of petroleum engineers, Trinidad, Spain.

3. Alizadeh $\mathrm{N}$, Mighani S, Hashemi kiasari H, Hemmati-Sarapardeh A, Kamari A (2013) Application of fast-SAGD in naturally rractured heavy oil reservoirs: A case study. Middle East oil \& Gas show (MEOS) $18^{\text {th }}$ Conference, Barhain.

4. Kamari A, Mohammadi $\mathrm{AH}$ (2014) Screening of enhanced oil recovery methods. Nova Science Publishers.

5. Kamari A, Nikookar M, Hemmati-Sarapardeh A, Sahranavard L, Mohammadi AH (2014) Screening of Potential Application of EOR Processes in a naturally fractured oil reservoir. Enhanced Oil Recovery: Methods, Economic benefits and impacts on the environment. Nova Science Publishers, USA.

6. Kamari A, Nikookar M, Sahranavard L, Mohammadi AH (2014) Efficient screening of enhanced oil recovery methods and predictive economic analysis. Neural Computing and Applications 25: 815-824

7. Kamari A, Hemmati-Sarapardeh A, Mohammadi AH, Hashemi-Kiasari $H$ Mohagheghian E (2015) On the evaluation of Fast-SAGD process in naturally fractured heavy oil reservoir. Fuel 143: 155-164.

8. Hemmati-Sarapardeh A, Khishvand M, Naseri A, Mohammadi AH (2013) Towards reservoir oil viscosity correlation. Chemical Engineering Science 90: $53-68$

9. Al-Marhoun MA (1988) PVT correlations for Middle East crude oils. J Pet Technol 40: 650-666.

10. Al-Marhoun MA (2004) Evaluation of empirically derived PVT properties fo Middle East crude oils. Journal of Petroleum Science and Engineering 42: 209 221.

11. Arabloo MA, Amooie A, Hemmati-Sarapardeh A, Ghazanfari MH, Mohammadi $\mathrm{AH}$ (2014) Application of constrained multi-variable search methods for prediction of PVT properties of crude oil systems. Fluid Phase Equilibria 363 : 121-130.

12. Asoodeh M, Bagheripour P (2012) Estimation of bubble point pressure from PVT data using a power-law committee with intelligent systems. Journal of Petroleum Science and Engineering 90: 1-11.

13. Elsharkawy $P(A M)$ An empirical model for estimating the saturation pressures of crude oils. J Pet Sci Eng 38: 57-77.

14. Elam FM (1957) Prediction of bubble point pressures and formation volume factors from field data. University of Texas, Austin, Texas.

15. Lasater J (1958) Bubble point pressure correlation. J Pet Technol 10: 65-67.

16. Vazquez M, Beggs HD (1980) Correlations for fluid physical property prediction. J Pet Technol 32: 968-970.

17. Ostermann R, Ehlig-Economides C, Owolabi O (1983) Correlations for the reservoir fluid properties of Alaskan crudes. University of Alaska.

18. Rollins JB, McCain Jr, Creeger TJ (1990) Estimation of solution GOR of black oils. J Pet Tech 42: 92-94.

19. Sutton RP, Farshad F (1990) Evaluation of empirically derived PVT properties for Gulf of Mexico crude oils. SPE Reservoir Engineering 5: 79-86.

20. Glaso O (1980) Generalized pressure-volume-temperature correlations. J Pet Tech 32: 785-795.

21. Dokla ME, Osman ME (1992) Correlation of PVT properties for UAE crudes. SPE formation evaluation 7: 41-46.

22. Omar M, Todd A (1993) Development of new modified black oil correlations for Malaysian crudes, in: SPE Asia Pacific oil and gas conference. Society of Petroleum Engineers.

23. Standing M (1947) A pressure-volume-temperature correlation for mixtures of California oils and gases. Drilling and Production Practice.

24. Petrosky G, Farshad F (1993) Pressure-volume-temperature correlations for Gulf of Mexico crude oils, in: SPE Annual Technical Conference and Exhibition. Society of Petroleum Engineers.

25. Elsharkawy AM, Elgibaly AA, Alikhan AA (1995) Assessment of the PVT correlations for predicting the properties of Kuwaiti crude oils. J Pet Sci Eng 13: $219-232$.

26. Ghetto GD, Paone F, Villa M (1994) Reliability analysis on PVT correlations, In: European Petroleum Conference. Society of Petroleum Engineers.

27. Khairy M, El-Tayeb M, Hamdallah M (1998) PVT correlations developed for Egyptian crudes. Oil and Gas Journal.

28. Velarde J, Blasingame T, McCain W (1999) Correlation of black oil properties at pressures below bubble-point pressure-a new approach. J Can Petrol Tech 38: 1-6.

29. Mazandarani MT, Asghari SM (2007) Correlations for predicting solution gas-oil ratio, bubble-point pressure and oil formation volume factor at bubble-point of Iran Crude Oils, In: European Congress of Chemical Engineering, Copenhagen.

30. Taghaz A, Eltaeb N, Alakhdar S (2008) Comparison study of published PVT correlations and its application to estimate reservoir fluid properties for Libyan oil reservoirs, in: Tenth Mediterranean Petroleum Conference and Exhibition. Libya. 
Citation: Kamari A, Zendehboudi S, Sheng JJ, Mohammadi AH, Ramjugernath D (2016) Rigorous Modeling of Solution Gas-Oil Ratios for a Wide Ranges of Reservoir Fluid Properties. J Pet Environ Biotechnol 7: 308. doi: 10.4172/2157-7463.1000308

31. Shafiie O, Moghadasi J, Shahbazian M, Zargani F (2012) Optimization of formation volume factor and solution gas-oil ratio correlations for southern Iranian oilfields using genetic algorithm. Journal of American Science 8: 19-25.

32. Kamari A, Arabloo M, Shokrollahi A, Gharagheizi F, Mohammadi AH (2015) Rapid method to estimate the minimum miscibility pressure (MMP) in live reservoir oil systems during $\mathrm{CO}_{2}$ flooding. Fuel 153: 310-319

33. Kamari A, Bahadori A, Mohammadi AH, Zendehboudi S (2014) Evaluating the unloading gradient pressure in continuous gas-lift systems during petroleum production operations. J Pet Sci Eng 32: 2961-2968.

34. Kamari A, Bahadori A, Mohammadi AH, Zendehboudi S (2015) New tools predict monoethylene glycol injection rate for natural gas hydrate inhibition. $J$ Loss Prev Process Ind 33: 222-231.

35. Kamari A, Gharagheizi F, Bahadori A, Mohammadi AH (2014) Determination of the equilibrated calcium carbonate (calcite) scaling in aqueous phase using a reliable approach. J Taiwan Inst Chem Eng 45: 1307-1313.

36. Kamari A, Mohammadi A, Bahadori A, Zendehboudi S (2014) A reliable model for estimating the wax deposition rate during crude oil production and processing. J of Pet Sci Tech 32: 2837-2844.

37. Kamari A, Mohammadi AH, Bahadori A, Zendehboudi S (2014) Prediction of Air Specific Heat Ratios at Elevated Pressures Using a Novel Modeling Approach. $\mathrm{J}$ of Chem Eng Tech 37: 2047-2055

38. Zendehboudi S, Shafiei A, Bahadori A, James LA, Elkamel A, et al. (2013) Asphaltene precipitation and deposition in oil reservoirs-Technical aspects, experimental and hybrid neural network predictive tools. Chem Eng Res Design.

39. Esfahani S, Baselizadeh S, Hemmati-Sarapardeh A (2015) On determination of natural gas density: Least square support vector machine modeling approach. J Nat Gas Sci Eng 22: 348-358.

40. Hosseinzadeh M, Hemmati-Sarapardeh A (2014) Towards a predictive model for estimating viscosity of ternary mixtures containing ionic liquids. Journal of Molecular Liquids 200: 340-348.

41. LINGO-Softwate (2011) Optimization Modeling Software for Linear, Nonlinear, and Integer Programming, LINDO Systems, LINGO Version 11, in, 2011.

42. Baniasadi H, Kamari A, Heidararabi S, Mohammadi AH, Hemmati-Sarapardeh A (2015) Rapid method for the determination of solution gas-oil ratios of petroleum reservoir fluids. J Nat Gas Sci Eng 24: 1-10.

43. Abdul-Majeed GH, Salman NH, Scarth B (1988) An empirical correlation for oil FVF prediction. J of Can Pet Technol.

44. Bello O, Reinicke K, Patil P (2008) Comparison of the performance of empirical models used for the prediction of the PVT properties of crude oils of the Niger delta. J of Pet Sci Technol 26: 593-609.

45. Mahmood MA, Al-Marhoun MA (1996) Evaluation of empirically derived PVT properties for Pakistani crude oils. J Pet Sci Eng 16: 275-290.

46. Moghadam JN, Salahshoor K, Kharrat K (2011) Introducing a new method for predicting PVT properties of Iranian crude oils by applying artificial neural networks. J of Pet Sci Technol 29: 1066-1079.

47. Obomanu D, Okpobiri G (1987) Correlating the PVT properties of Nigerian crudes. J Energy Resour Technol 109: 214-217.

48. Chuang YF, Lee HT, Lai YC (2012) Item-associated cluster assignment mode on storage allocation problems. Computers \& Industrial Engineering 63: 1171 1177 .

49. Carvalho M, Lozano MA, Serra LM, Wohlgemuth $\vee(2012)$ Modeling simple trigeneration systems for the distribution of environmental loads. Environmental Modelling \& Software 30: 71-80.

50. Vidal D, Blobel J, Pérez Y, Thormann M, Pons M (2007) Structure-based discovery of new small molecule inhibitors of low molecular weight protein tyrosine phosphatase. Eur J Med Chem 42: 1102-1108.

51. Z. Miao (2011) Discussion of optimize method of fire alarm dispatching based on operation research principle. Procedia Engineering 11: 689-694.

52. Chen G, Fu K, Liang Z, Sema T, Li C, et al. (2014) The genetic algorithm based back propagation neural network for MMP prediction in CO 2-EOR process. Fuel 126: 202-212

53. Macary S, El-Batanoney M (1993) Derivation of PVT correlations for the Gulf of Suez crude oils. Sekiyu Gakkai Shi 36: 472-478.

54. Kartoatmodjo T, Schmidt Z (1994) Large data bank improves crude physical property correlations. Oil \& Gas Journal.

55. Al-Shammasi A (1999) Bubble point pressure and oil formation volume factor correlations, in: SPE Middle East Oil Show \& Conference, pp: 241-256.

56. Dindoruk B, Christman PG (2004) PVT properties and viscosity correlations for Gulf of Mexico oils. SPE Reservoir Evaluation \& Engineering 7: 427-437.

57. Mohammadi AH, Gharagheizi F, Eslamimanesh A, Richon D (2012) Evaluation of experimental data for wax and diamondoids solubility in gaseous systems. Chemical Engineering Science.

58. Gharagheizi F, Eslamimanesh A, Ilani-Kashkouli P, Mohammadi AH, Richon D (2012) QSPR molecular approach for representation/prediction of very large vapor pressure dataset. Chemical Engineering Science, 76: 99-107.

59. Rousseeuw PJ, Leroy AM (2003) Robust regression and outlier detection. Wiley. 